\title{
The Optimal Indication for Testosterone Replacement Therapy in Late Onset Hypogonadism
}

\author{
Yu Seob Shin 1,2,3,4 (D) and Jong Kwan Park 1,2,3,4,* \\ 1 Department of Urology, Chonbuk National University Medical School, Jeonju 54907, Korea; \\ ball1210@hanmail.net \\ 2 Research Institute of Clinical Medicine, Chonbuk National University, Jeonju 54907, Korea \\ 3 Biomedical Research Institute, Chonbuk National University Hospital, Jeonju 54907, Korea \\ 4 Clinical Trial Center of Medical Device, Chonbuk National University Hospital, Jeonju 54907, Korea \\ * Correspondence: rain@chonbuk.ac.kr; Tel.: +82-63-250-1510; Fax: +82-63-250-1564
}

Received: 2 January 2019; Accepted: 3 February 2019; Published: 7 February 2019

\begin{abstract}
The use of testosterone replacement therapy (TRT) for late-onset hypogonadism (LOH) is increasing every year; however, the literature shows that many men are using testosterone $(\mathrm{T})$ without a clear indication. Previous studies have estimated that up to $25 \%$ of men who receive TRT do not have their $\mathrm{T}$ tested prior to initiation of the therapy. Given the growing concern and need for proper TRT, clinicians need evidence-based information that informs them on the optimal indication for TRT in $\mathrm{LOH}$ patients. The diagnosis of $\mathrm{LOH}$ requires the presence of characteristic signs and symptoms, in combination with decreased serum total testosterone (TT). Based on the recent guidelines by the International Society for the Study of Aging Male (ISSAM), the European Association of Urology (EAU), the European Society of Endocrinology (ESE), the European Academy of Andrology (EAA), and the American Association of Urology (AUA), a TT of $250-350 \mathrm{ng} / \mathrm{dL}$ is the proper threshold value to define low $\mathrm{T}$. The optimal indication for TRT in $\mathrm{LOH}$ is the presence of signs and symptoms of hypogonadism, and low T without contraindications for TRT.
\end{abstract}

Keywords: indication; hypogonadism; testosterone

\section{Introduction}

Late-onset hypogonadism $(\mathrm{LOH})$ is characterized by low testosterone $(\mathrm{T})$ levels and clinical symptoms [1-6]. Sexual symptoms and fatigue are the earliest and most common presentations [1-3]. Other symptoms include depression, sleep alterations, poor concentration, and metabolic disorders are seen at borderline T levels [4-6]. The Total testosterone (TT) and free testosterone (FT) concentrations decrease with increasing age in men [7]. LOH is the result of a gradual drop in T; a steady decline in $\mathrm{T}$ levels of about $1 \%$ per year is well documented in men [8]. However, decreases in $\mathrm{T}$ concentrations with age are gradual and vary between individuals, with higher rates of decline in men with adiposity and comorbid diseases [7]. Testosterone has anabolic effects that include growth of muscle mass and strength, increased bone density and strength, and stimulation of linear growth, production of blood, and bone maturation [9]. In $\mathrm{LOH}$, the anabolic effect of $\mathrm{T}$ is reduced due to its deficiency.

Hypogonadism can be divided into two major categories [10]. Primary hypogonadism, also known as primary testicular failure, originates from a problem in the testicles. Secondary hypogonadism indicates a problem in the hypothalamus or the pituitary gland, parts of the brain that signal the testicles to produce testosterone. $\mathrm{LOH}$ has the combined features of both primary and secondary hypogonadism.

Demographic data clearly demonstrate that the percentage of older adults in the general population is increasing [11]. Androgen deficiency in the aging male has become a topic of increasing 
interest and debate throughout the world [12]. Furthermore, social interest in testosterone replacement therapy has increased over the past few decades. To provide appropriate guidelines for optimal indication of treatment for $\mathrm{LOH}$ in aging men, we summarized the recent guidelines by the International Society for the Study of Aging Male (ISSAM), the European Association of Urology (EAU), the European Society of Endocrinology (ESE), the European Academy of Andrology (EAA), the American Association of Urology (AUA), and the Canadian Men's Health Foundation.

\section{Diagnosis}

\subsection{ISSAM Guidelines}

The diagnosis of hypogonadism requires the presence of characteristic signs and symptoms (evidence level: Level 2, Grade A), in combination with decreased serum concentration of testosterone [13]. Symptoms of hypogonadism may be categorized as sexual or non-sexual. Sexual symptoms include erectile dysfunction, diminished frequency of morning erections, and decrease in sexual thoughts (low libido), as well as difficulty in achieving orgasm and reduced intensity of orgasm (Table 1) [14]. Non-sexual symptoms include fatigue, impotence, impaired concentration, depression, and decreased sense of vitality and/or well-being. Signs of hypogonadism also include anemia, osteopenia and osteoporosis, abdominal obesity, and metabolic syndrome [15]. Principally, the clinician has to distinguish between forms of congenital hypogonadism, which can be congenital (e.g., Kallmann syndrome, Klinefelter syndrome) or acquired (e.g., anorchia due to trauma or orchiectomy, pituitary lesions/tumors, or LOH), requiring lifelong hormonal therapy, and forms of hypogonadism that might be reversible [13]. The latter, potentially reversible forms of hypogonadism are most often found to co-existence with metabolic disorders, such as obesity/type 2 diabetes mellitus (T2DM), inflammatory diseases (e.g., chronic obstructive pulmonary disease, chronic inflammatory bowel diseases), and anemia, or psychological problems, such as depression or stress.

Table 1. Symptoms and signs associated with LOH.

\begin{tabular}{ccc}
\hline Physical & Cognitive & Sexual \\
\hline $\begin{array}{c}\text { Anemia } \\
\text { Reduced energy }\end{array}$ & Depressive symptoms & Reduced sex drive \\
\hline Reduced endurance & Cognitive dysfunction & Reduced erectile function \\
\hline Diminished work performance & Reduced motivation & \\
\hline Diminished physical performance & Poor concentration & \\
\hline Loss of body hair & Poor memory \\
\hline Reduced beard growth & Irritability \\
\hline Fatigue & \\
\hline Reduced lean muscle mass & \\
\hline Obesity & \\
\hline
\end{tabular}

Screening questionnaires on male symptomatic hypogonadism, although sensitive, have low specificity. Morley et al. compared the most commonly-used questionnaires in 148 men using bioavailable testosterone (BT) as the biochemical "gold standard" for the diagnosis of hypogonadism and found the sensitivity to be $97 \%$ for the Androgen Deficiency in the Aging Male questionnaire (ADAM), 83\% for the Aging Male's Symptoms scale (AMS), and 60\% for the Massachusetts Male Aging Study questionnaire (MMAS). Specificity was 30\% for the ADAM, 59\% for the MMAS, and 39\% for the AMS [16]. Despite having low specificity, the AMS and other male hypogonadism questionnaires may be useful to assess the presence and severity of symptoms as a prerequisite for initiating and monitoring clinical response to testosterone replacement therapy (TRT) [13]. 
Physical examination of patients with suspected hypogonadism should include an assessment of the amount and distribution of body hair (including beard growth and pubic hair), presence of acanthosis nigricans, associated with insulin resistance, presence, and degree of breast enlargement, size and consistency of the testes, abnormalities in the scrotum and size, appearance of the penis, and presence of subcutaneous plaque [13]. The prostate should be examined in older patients for size, consistency, symmetry, and presence of nodules or induration; it should be noted that the prostate may be enlarged in older men, despite a low testosterone level [17]. Weight, height, body mass index (BMI), and waist circumference should also be measured, since signs and symptoms potentially indicative of $\mathrm{T}$ deficiency in men include height loss, reduced muscle bulk and strength, and increased body fat, particularly increased BMI and abdominal fat accumulation [18].

In patients at risk or suspected of hypogonadism, a thorough physical and biochemical work-up is recommended (evidence level: Level 2, Grade A). The key laboratory tests to confirm the diagnosis of hypogonadism are serum TT and FT. Transient decreases of serum T levels can occur due to acute illnesses [19], and this should be excluded by careful clinical evaluation and repeated hormone measurements.

The ISSAM guidelines recommend $12.1 \mathrm{nmol} / \mathrm{L}$ as the lower limit of normal total testosterone [13]. However, due to individual differences in $\mathrm{T}$ sensitivity, some men may exhibit symptoms of hypogonadism with TT concentrations above this threshold and may benefit from TRT. TRT may be reasonably offered to symptomatic men with $\mathrm{T}$ concentrations lower than $12 \mathrm{nmol} / \mathrm{L}$, based on clinical judgment. Although the ISSAM guidelines for FT levels have not yet been set, the guidelines mention that FT levels as low as $225 \mathrm{pmol} / \mathrm{L}(65 \mathrm{pg} / \mathrm{mL})$ have been recommended as the normal range lower limit and, together with the presence of one or more hypogonadal symptoms, can provide supportive evidence for TRT (evidence level: Level 2, Grade B) [20]. Collection of serum samples for TT determinations is preferred between the morning hours of 7:00 and 11:00 [21] (evidence level: Level 2a, Grade A). Free testosterone or BT should be considered when the TT concentration does not correspond with clinical presentation, since individual variation in sex hormone binding globulin (SHBG) concentrations may influence TT results. Measurement of serum SHBG, together with a reliable measurement of TT, allows for the determination of the calculated free T level (evidence level: Level 2b, Grade A) [22].

\subsection{EAU Guidelines}

Low levels of circulating androgens may be associated with specific signs and symptoms. The most prevalent symptoms of $\mathrm{LOH}$ are reduced sexual desire and sexual activity, ED, loss of vigor, and mood changes [23]. Signs and symptoms of LOH vary depending on age of onset, duration, and severity of the deficiency. Reference ranges for the lower normal level of $\mathrm{T}(2.5 \%)$ have been compiled from three large community-based samples and suggest a cut-off of $12.1 \mathrm{nmol} / \mathrm{L}$ for TT and $243 \mathrm{pmol} / \mathrm{L}$ for FT, to distinguish between normal levels and levels possibly associated with deficiency [24]. It should, however, be noted that these symptoms are also found in men with normal T levels and may have causes other than androgen deficiency. In men aged 40-79 years, the strongest predictor for hypogonadism was three sexual symptoms (decreased sexual thoughts, weakened morning erections, and ED) and either a TT level of $<8 \mathrm{nmol} / \mathrm{L}$, or serum $\mathrm{T}$ in the range of 8-11 nmol/L, and FT <220 pmol/L [25].

Laboratory testing of $\mathrm{T}$ should reflect the diurnal variation of testosterone. In most cases, two'morning (7:00-11:00) samples are sufficient, but further evaluation should be triggered if the difference between the two measurements is $>20$ percent [26]. In cases with discrepancy between $\mathrm{T}$ levels and symptoms, the FT level should be analyzed [15]. For determination of FT levels, the calculation of FT, with the help of SHBG, is recommended [15].

In $\mathrm{LOH}$, published questionnaires are unreliable, have low specificity, and are not effective for case findings [27]. Assessment of BMI, the waist:hip ratio, body hair, male pattern hair loss, presence of 
gynecomastia, testicular size, and examination of the penis, as well as examination of prostate should be included [15].

\subsection{ESE and EAA Guidelines}

The ESE and the EAA suggest against routinely prescribing TRT for all men 65 years or older with low $\mathrm{T}$ concentrations [18]. TRT should be recommended in men $>65$ years who have symptoms or conditions suggestive of $\mathrm{T}$ deficiency (such as low libido or unexplained anemia) and consistently and unequivocally low morning T. Low libido, ED, and less specific symptoms (such as fatigue, irritability, depressed mood, poor concentration, reduced physical performance, and sleep disturbance) are associated with low T concentrations [28]. In the European Male Aging Study (a cohort study of community-dwelling middle-aged and older men in Europe), only sexual symptoms (poor morning erections, decreased libido, and ED) had a syndromic association with TT concentrations of $320 \mathrm{ng} / \mathrm{dL}$ $(11 \mathrm{nmol} / \mathrm{L})$ and FT of $64 \mathrm{pg} / \mathrm{mL}(220 \mathrm{pmol} / \mathrm{L})$ (after adjusting for age) [7]. Testosterone alone is required to maintain lean mass and muscle size and strength; estradiol is required to prevent increases in fat mass and vasomotor symptoms; and both $\mathrm{T}$ and estradiol are required to maintain sexual function and bone mineral density (BMD) [29]. Testosterone concentrations exhibit significant diurnal and day-to-day variations and may be suppressed by food intake or glucose. Therefore, clinicians should measure TT concentrations on two separate mornings when the patient is fasting. Clinicians should use an accurate and reliable method, optimally an assay that has been certified by an accuracy-based standardization.

\subsection{AUA Guidelines}

Clinicians should use a TT level below $300 \mathrm{ng} / \mathrm{dL}$ as a reasonable cut-off in support of the diagnosis of low testosterone (moderate recommendation; evidence level: Grade B) [30]. The diagnosis of low T should be made only after two TT measurements are taken on separate occasions, with both conducted in early morning (strong recommendation; evidence level: Grade A). The clinical diagnosis of T deficiency is only made when patients have low TT levels combined with symptoms and/or signs (moderate recommendation; evidence level: Grade B). Clinicians should consider measuring TT in patients with a history of unexplained anemia, bone density loss, diabetes, exposure to chemotherapy, exposure to testicular radiation, HIV / AIDS, chronic narcotic use, male infertility, pituitary dysfunction, and chronic corticosteroid use, even in the absence of signs or symptoms associated with T deficiency (moderate recommendation; evidence level: Grade B). The use of validated questionnaires is not currently recommended to either define which patients are candidates for $\mathrm{T}$ therapy or to monitor symptom response in patients on $\mathrm{T}$ therapy (conditional recommendation; evidence level: Grade $\mathrm{C}$ ). In the patients with low testosterone, clinicians should measure serum luteinizing hormone levels (strong recommendation; evidence level: Grade A). Serum prolactin levels should be measured in patients with low $\mathrm{T}$ levels, combined with low or low/normal luteinizing hormone levels (strong recommendation; evidence level: Grade A). Patients with persistently high prolactin levels of unknown etiology should undergo evaluation for endocrine disorders (strong recommendation; evidence level: Grade A). Serum estradiol should be measured in T-deficient patients who present with breast symptoms or gynecomastia, prior to the commencement of $\mathrm{T}$ therapy (expert opinion). Men with $\mathrm{T}$ deficiency who are interested in fertility should have a reproductive health evaluation performed prior to treatment (moderate recommendation; evidence level: Grade B). Prostate-specific antigen (PSA) should be measured in men over 40 years of age prior to commencement of $\mathrm{T}$ therapy to exclude a prostate cancer diagnosis (clinical principle).

\subsection{Canadian Men's Health Foundation Multidisciplinary Guidelines}

Diagnosis of $\mathrm{T}$ deficiency syndrome requires the presence of the clinical manifestations of $\mathrm{T}$ deficiency, together with documented $\mathrm{T}$ levels below the local laboratory ranges [31]. The initial biochemical test should be TT level measured in serum samples taken in the morning; determinations 
of BT or FT should be restricted to patients with equivocally low TT levels (strong recommendation; high-quality evidence). $\mathrm{T}$ levels should be measured with the use of $\mathrm{T}$ assays traceable to internationally-recognized standardized reference material; commercial assays should be certified by the testosterone standardization program of the U.S. Centers for Disease Control and Prevention (strong recommendation; high-quality evidence). In men with ED and no other manifestations of $\mathrm{T}$ deficiency syndrome, they suggest investigation. Treatment is recommended for $\mathrm{T}$ deficiency syndrome; the choice of treatment is based on product safety, efficacy, tolerability, cost, and the absence of contraindications. Men with testosterone deficiency syndrome and stable cardiovascular disease (CVD) are candidates for TRT (weak recommendation; low-quality evidence). Hypogonadal men with successfully-treated prostate cancer (PCa) may be candidates for $\mathrm{T}$ supplementation; these patients require referral to a specialist, because treatment involves close monitoring by a physician with expertise in the risks and benefits of $\mathrm{T}$ therapy. Men with a history of breast cancer are not candidates for testosterone replacement therapy (weak recommendation; moderate-level of evidence). They recommend treatment with a PDE-5 inhibitor in men with T deficiency syndrome and persistent $\mathrm{ED}$ that is adequately treated with $\mathrm{T}$ (strong recommendation; high-quality evidence). Regular monitoring for clinical and biochemical response, and for adverse effects, to TRT is essential, particularly during the first year of treatment.

\section{Optimal Indication for TRT}

TRT for LOH is increasing every year; however, it is clear from the literature that many men are using $\mathrm{T}$ without a clear indication [32-34]. Previous studies estimated that up to $25 \%$ of men who received TRT did not have their T tested prior to initiation of TRT [32,33]. Given the growing concern and need for proper TRT, a need exists to define a TT threshold to guide clinicians in the diagnosis and management of $\mathrm{LOH}$ patients. Based on the recent guidelines by ISSAM, EAU, ESE, EAA, and AUA, a TT of $250-350 \mathrm{ng} / \mathrm{dL}$ is the proper threshold value to define low testosterone $[13,15,18,30]$ (Table 2). Adherence to this recommendation can increase clinicians' confidence regarding the risk:benefit ratio of TRT, explicitly placing a higher value on maximizing true benefit and reducing clinically-inappropriate use of TRT (Figure 1). The prevalent confusion about the diagnosis of T deficiency, the inappropriate use of TRT, and the recent reports of potentially increased risk of serious adverse effects with the use of TRT indicate an important need for guidance among health professionals in the management of testosterone deficiency. Although direct measurement of FT has a generally good correlation with equilibrium dialysis, it is not reliable because of a high coefficient of variation [12,35]. Given that the direct method for FT measurement is also time consuming and labor intensive, recent guidelines do not recommend using FT measurements as the primary diagnostic method for $\mathrm{LOH}[13,15,18,30]$. However, in cases with discrepancy between T levels and symptoms, FT levels should be analyzed [15].

Table 2. The guidelines for the diagnosis of the optimal indication of treatment for $\mathrm{LOH}$.

\begin{tabular}{ccccc}
\hline Guideline & Threshold of TT & Threshold of FT & $\begin{array}{c}\text { How Many Times } \\
\text { T Needs to } \\
\text { Measured }\end{array}$ & Questionnaire \\
\hline ISSAM & $12.1 \mathrm{nmol} / \mathrm{L}$ & $225 \mathrm{pmol} / \mathrm{L}$ & Not suggested & Recommended \\
\hline EAU & $12.1 \mathrm{nmol} / \mathrm{L}$ & $243 \mathrm{pmol} / \mathrm{L}$ & 2 times & Not recommended \\
\hline ESE and EAA & $320 \mathrm{ng} / \mathrm{dL}$ & $220 \mathrm{pmol} / \mathrm{L}$ & 2 times & Not recommended \\
\hline AUA & $300 \mathrm{ng} / \mathrm{dL}$ & Not suggested & 2 times & Not recommended \\
\hline $\begin{array}{c}\text { Canadian Men's } \\
\text { Health Foundation }\end{array}$ & Not suggested & Not suggested & Not suggested & Not recommended \\
\hline $\begin{array}{l}\text { LOH: late-onset hypogonadism, T: testosterone, TT: total testosterone, FT: free testosterone, ISSAM: International } \\
\text { Society for the Study of Aging Male, EAU: European Association of Urology, ESE: European Society of Endocrinology, } \\
\text { EAA: European Academy of Andrology, AUA: American Association of Urology. }\end{array}$
\end{tabular}




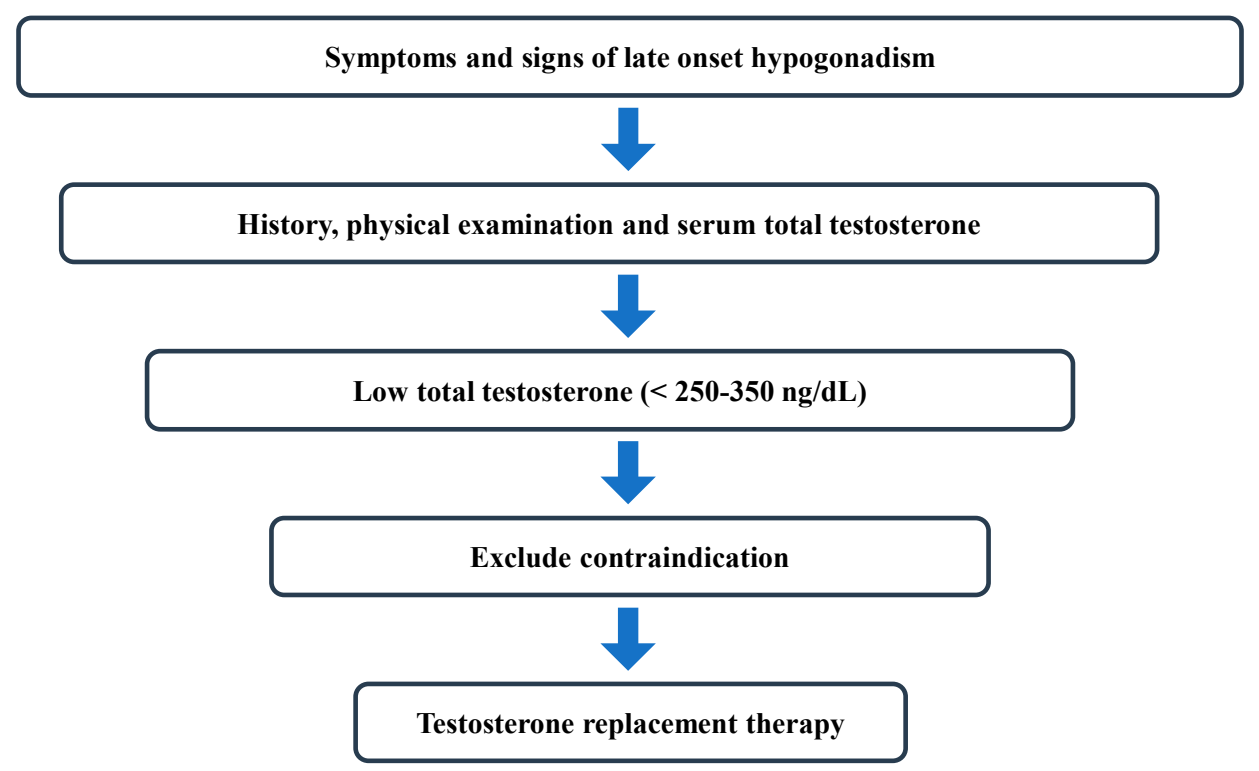

Figure 1. Flowchart for the management of late-onset hypogonadism.

There are inherent challenges to $\mathrm{T}$ measurements due to the health status of patients at the time of testing, circadian rhythms in T production, intra-individual variability, and inconsistencies in the assays themselves. To ensure accuracy and precision, it is necessary to obtain at least two serum TT measurements in early morning to diagnose patients with $\mathrm{LOH}[13,15,18,30]$. The sample collection for $\mathrm{T}$ measurement occurs between 7:00 and 11:00, or within $3 \mathrm{~h}$ after waking in the case of shift workers [31]. Intra-individual T variability is significant, and repeated measures can fluctuate $65-153 \%$ between tests, depending on the assay used; however, performing two or three measurements can reduce this variability by 30-43\%, respectively [36]. T levels should be measured with the use of $\mathrm{T}$ assays traceable to internationally-recognized standardized reference materials [31].

Low TT alone does not define $\mathrm{LOH}$. The diagnosis of $\mathrm{LOH}$ must include the presence of signs and/or symptoms associated with low T, in combination with documented low TT levels (Table 1). Clinicians should refrain from measuring $\mathrm{T}$ levels in patients who are asymptomatic, do not exhibit signs related to low $\mathrm{T}$, or do not have any comorbid conditions that are associated with low $\mathrm{T}$.

Several validated questionnaires are used as screening tools to identify men of $\mathrm{LOH}$, but there is an absence of concordance among the questionnaires as to which symptoms are related to low $\mathrm{T}$ or to what extent these symptoms improve with TRT. Specificities and sensitivities vary greatly among these tests, making them ill-suited for screening or for use as a surrogate for $\mathrm{T}$ laboratory testing. Higher sensitivities and lower specificities have been reported for the AMS and ADAM, with sensitivities/specificities of $81 \% / 19 \%$ and $97 \% / 39 \%$, respectively, for each questionnaire; while the MMAS and ANDROTEST exhibit lower sensitivities and higher specificities, with sensitivities/specificities of $60 \% / 53 \%$ and $71 \% / 65 \%$, respectively [37].

Prior to commencing TRT, all patients should undergo a baseline measurement of hemoglobin $(\mathrm{Hb}) /$ hematocrit $(\mathrm{Hct})$. If the Hct exceeds $50 \%$, clinicians should consider withholding TRT until the etiology of the high Hct is explained [38]. Men with elevated Hct and on-treatment low/normal total and free $\mathrm{T}$ levels should be referred to a hematologist for further evaluation, and possible coordination of phlebotomy. Testosterone has a stimulating effect on erythropoiesis, and elevation of $\mathrm{Hb} / \mathrm{Hct}$ is the most frequent adverse event related to TRT [39]. During TRT, levels of $\mathrm{Hb} / \mathrm{Hct}$ generally rise for the first six months, then tend to plateau [40].

PSA should be measured in men over 40 years of age prior to commencement of TRT to exclude a prostate cancer diagnosis [41]. PSA secretion is an androgen-dependent phenomenon, and the rise of PSA levels in patients on TRT is primarily dependent on baseline TT levels. A previous study 
found that men with lower baseline $\mathrm{T}$ levels were more likely to experience PSA level increases after TRT [42]. In that study, participants $(N=451)$ received $5-10 \mathrm{~g}$ of $1 \% \mathrm{~T}$ gel daily for 12 months. Patients were divided into two groups: A ( $n=197$ with TT $<250 \mathrm{ng} / \mathrm{dL})$ and $\mathrm{B}(n=254$ with TT $\geq 250 \mathrm{ng} / \mathrm{dL})$. In Group A, but not Group B, baseline PSA levels correlated significantly with total testosterone levels $(r=0.2 ; p<0.01)$. At the end of follow-up, PSA increased significantly in Group A ( $21.9 \%$ change; $0.19 \pm 0.61 \mathrm{ng} / \mathrm{mL} ; p=0.02)$, but not in Group B $(14.1 \%$ change; $0.28 \pm 1.18 \mathrm{ng} / \mathrm{mL} ; p=0.06)$, with the greatest PSA change observed after one month of treatment [42].

The effects of TRT on cardio vascular disease (CVD) remain a point of concern. Ferrucci et al. showed that low $\mathrm{T}$ levels had an independent influence on the development of anemia in older adults [43]. T stimulates the production of erythropoietin-responsive cells and burst-forming units in the bone marrow, which boosts iron absorption and erythropoiesis [44]. The effects of $T$ on the bone marrow affecting the hematopoietic growth factors and iron absorption show the association between $\mathrm{T}$ and erythropoiesis. In an earlier study, our data demonstrated that subjects with low TT and FT levels had low $\mathrm{Hb}$ and Hct levels [45]. This result suggests that TT and FT may play a significant role in erythropoiesis. According to a recent study, TRT in older men with low T levels significantly increased $\mathrm{Hb}$ levels of those with unexplained anemia, as well as those with anemia from known causes [46]. Measurement of T levels might be considered in men 65 years or older who have unexplained anemia and symptoms of low $\mathrm{T}$ levels. Although men with hypogonadism were not always anemic in our previous study, the association between low testosterone and low $\mathrm{Hb}$ levels was statistically significant [45]. Furthermore, our previous study noted that the prevalence of anemia decreased, and patients with anemia showed increased erythropoietin after TRT [47]. TRT may be effective in men with hypogonadism to reduce the incidence of anemia and the CVD associated with anemia $[47,48]$.

Little is yet known about the clinical utility of serum $\mathrm{T}$ levels as a predictor of disease progression in PCa patients. Recently, Ferro et al. [49] showed that low serum T levels $(<300 \mathrm{ng} / \mathrm{dL})$ were significantly associated with upgrading, upstaging, unfavorable disease, and positive surgical margins in PCa patients. On this basis, TT should be measured in patients with a localized PCa, in particularly when active surveillance or nerve-sparing surgery is considered [49]. Furthermore, growing evidence supports the idea that a decreased serum $\mathrm{T}$ concentration, related to different metabolic disorders including obesity and metabolic syndrome, may modulate PCa aggressiveness [50]. Furthermore, Cobeli et al. [51] showed that BMI was significantly associated with upgrading, upstaging, and seminal vesicle invasion in men with low-risk PCa. These data further support the idea that obesity is associated with PCa aggressiveness [50,51].

\section{Conclusions}

The diagnosis of $\mathrm{LOH}$ requires the presence of characteristic signs and symptoms, in combination with decreased serum TT. Based on the recent guidelines by ISSAM, EAU, ESE, EAA, and AUA, a TT of $250-350 \mathrm{ng} / \mathrm{dL}$ is the proper threshold value to define low testosterone. The optimal indication of TRT for LOH is the presence of signs and symptoms and of hypogonadism and low T without contraindication for TRT.

Author Contributions: Y.S.S. and J.K.P. conceived of and designed the experiments; Y.S.S. and J.K.P. performed the experiments; Y.S.S. and J.K.P. analyzed the data; Y.S.S. and J.K.P. wrote and edited the paper.

Funding: This study was supported by grants from the Korean Healthcare Technology R\&D Project, Ministry for Health, Welfare, \& Family Affairs, Republic of Korea (HI14C0018).

Conflicts of Interest: The Korean Healthcare Technology R\&D Project, Ministry for Health, Welfare \& Family Affairs, Republic of Korea, had no role in the design or conduct of the study; collection, management, analysis, or interpretation of the data; nor preparation, review, or approval of the manuscript. The content of this article is solely the responsibility of the authors and does not necessarily represent the official views of the Korean Healthcare Technology R\&D Project, Ministry for Health, Welfare, \& Family Affairs, Republic of Korea. All researchers are receiving support from this grant, but there are no financial or other potential conflicts of interest to declare. 


\section{Abbreviations}

ADAM Androgen Deficiency in the Aging Male questionnaire

AMS Aging Male's Symptoms scale

AUA American Association of Urology

BMD bone mineral density

BMI body mass index

BT bioavailable testosterone

CVD cardiovascular disease

EAA European Academy of Andrology

EAU European Association of Urology

ED erectile dysfunction

ESE European Society of Endocrinology

FT free testosterone

$\mathrm{Hb}$ hemoglobin

Hct hematocrit

ISSAM International Society for the Study of Aging Male

$\mathrm{LOH}$ late-onset hypogonadism

MMAS Massachusetts Male Aging Study questionnaire

PCa prostate cancer

PSA prostate-specific antigen

SHBG sex hormone binding globulin

$\mathrm{T}$ testosterone

TRT testosterone replacement therapy

TT total testosterone

\section{References}

1. Bassil, N.; Alkaade, S.; Morley, J.E. The benefits and risks of testosterone therapy: A review. Ther. Clin. Risk Manag. 2009, 5, 427-448. [PubMed]

2. Choi, S.W.; Jeon, S.H.; Kwon, E.B.; Zhu, G.Q.; Lee, K.W.; Choi, J.B.; Jeong, H.C.; Kim, K.S.; Bae, S.R.; Bae, W.J.; et al. Effect of Korean Herbal Formula (Modified Ojayeonjonghwan) on Androgen Receptor Expression in an Aging Rat Model of Late Onset Hypogonadism. World J. Mens Health 2019, 37, 105-112. [CrossRef] [PubMed]

3. Traish, A.M.; Johansen, V. Impact of Testosterone Deficiency and Testosterone Therapy on Lower Urinary Tract Symptoms in Men with Metabolic Syndrome. World J. Mens Health 2018, 36, 199-222. [CrossRef]

4. Hackett, G. Type 2 Diabetes and Testosterone Therapy. World J. Mens Health 2019, 37, 31-44. [CrossRef]

5. Nam, Y.S.; Lee, G.; Yun, J.M.; Cho, B. Testosterone Replacement, Muscle Strength, and Physical Function. World J. Mens Health 2018, 36, 110-122. [CrossRef]

6. Park, H.J.; Lee, K.S.; Lee, E.K.; Park, N.C. Efficacy and Safety of a Mixed Extract of Trigonella foenum-graecum Seed and Lespedeza cuneata in the Treatment of Testosterone Deficiency Syndrome: A Randomized, Double-Blind, Placebo-Controlled Clinical Trial. World J. Mens Health 2018, 36, 230-238. [CrossRef] [PubMed]

7. Wu, F.C.; Tajar, A.; Beynon, J.M.; Pye, S.R.; Silman, A.J.; Finn, J.D.; O'Neill, T.W.; Bartfai, G.; Casanueva, F.F.; Forti, G.; et al. Identification of late-onset hypogonadism in middle-aged and elderly men. N. Engl. J. Med. 2010, 363, 123-135. [CrossRef]

8. Samaras, N.; Papadopoulou, M.A.; Samaras, D.; Ongaro, F. Off-label use of hormones as an antiaging strategy: A review. Clin. Interv. Aging 2014, 9, 1175-1186. [CrossRef]

9. Yialamas, M.A.; Hayes, F.J. Androgens and the ageing male and female. J. Clin. Endocrinol. Metab. 2003, 17, 223-236. [CrossRef]

10. Kumar, P.; Kumar, N.; Thakur, D.S.; Patidar, A. Male hypogonadism: Symptoms and treatment. J. Adv. Pharm. Technol. Res. 2010, 1, 297-301. [CrossRef]

11. Waite, L.J. The Demographic Faces of the Elderly. Popul. Dev. Rev. 2004, 30, 3-16. 
12. Wang, C.; Nieschlag, E.; Swerdloff, R.; Behre, H.M.; Hellstrom, W.J.; Gooren, L.J.; Kaufman, J.M.; Legros, J.J.; Lunenfeld, B.; Morales, A.; et al. Investigation, treatment and monitoring of late-onset hypogonadism in males: ISA, ISSAM, EAU, EAA and ASA recommendations. Eur. J. Endocrinol. 2008, 159, 507-514. [CrossRef] [PubMed]

13. Lunenfeld, B.; Mskhalaya, G.; Zitzmann, M.; Arver, S.; Kalinchenko, S.; Tishova, Y.; Morgentaler, A. Recommendations on the diagnosis, treatment and monitoring of hypogonadismin men. Aging Male 2015, 18, 5-15. [CrossRef] [PubMed]

14. Lunenfeld, B.; Arver, S.; Moncada, I.; Rees, D.A.; Schulte, H.M. How to help the aging male? Current approaches to hypogonadism in primary care. Aging Male 2012, 15, 187-197. [CrossRef]

15. Dohle, G.R.; Arver, S.; Bettocchi, C.; Jones, T.H.; Kliesch, S. EAU 2018 guideline on male hypogonadism. Available online: http:/ / www.uroweb.org/guideline/male-hypogonadism/ (accessed on 16 June 2018).

16. Morley, J.E.; Perry, H.M., III; Kevorkian, R.T.; Patrick, P. Comparison of screening questionnaires for the diagnosis of hypogonadism. Maturitas 2006, 53, 424-429. [CrossRef] [PubMed]

17. Brunton, S.A.; Sadovsky, R. Late-onset male hypogonadism and testosterone replacement therapy in primary care. J. Fam. Pract. 2010, 59, 1-8.

18. Bhasin, S.; Brito, J.P.; Cunningham, G.R.; Hayes, F.J.; Hodis, H.N.; Matsumoto, A.M.; Snyder, P.J.; Swerdloff, R.S.; Wu, F.C.; Yialamas, M.A. Testosterone therapy in men with hypogonadism: An Endocrine Society clinical practice guideline. J. Clin. Endocrinol. Metab. 2018, 103, 1-30. [CrossRef] [PubMed]

19. Isidori, A.M.; Lenzi, A. Risk factors for androgen decline in older males: Lifestyle, chronic diseases and drugs. J. Endocrinol. Invest. 2005, 28, 14-22.

20. Rosner, W.; Auchus, R.J.; Azziz, R.; Sluss, P.M.; Raff, H. Utility, limitations, and pitfalls in measuring testosterone: An Endocrine Society Position Statement. J. Clin. Endocrinol. Metab. 2007, 92, 405-413. [CrossRef]

21. Diver, M.J.; Imtiaz, K.E.; Ahmad, A.M.; Vora, J.P.; Fraser, W.D. Diurnal rhythms of serum total, free and bioavailable testosterone and of SHBG in middleaged men compared with those in young men. Clin. Endocrinol. 2003, 58, 710-717. [CrossRef]

22. Vermeulen, A.; Verdonck, L.; Kaufman, J.M. A critical evaluation of simple methods for the estimation of free testosterone in serum. J. Clin. Endocrinol. Metab. 1999, 84, 3666-3672. [CrossRef]

23. Hall, S.A.; Esche, G.R.; Araujo, A.B.; Travison, T.G.; Clark, R.V.; Williams, R.E.; McKinlay, J.B. Correlates of low testosterone and symptomatic androgen deficiency in a population-based sample. J. Clin. Endocrinol. Metab. 2008, 93, 3870-3877. [CrossRef] [PubMed]

24. Bhasin, S.; Pencina, M.; Jasuja, G.K.; Travison, T.G.; Coviello, A.; Orwoll, E.; Wang, P.Y.; Nielson, C.; Wu, F.; Tajar, A.; et al. Reference ranges for testosterone in men generated using liquid chromatography tandem mass spectrometry in a community-based sample of healthy nonobese young men in the Framingham Heart Study and applied to three geographically distinct cohorts. J. Clin. Endocrinol. Metab. 2011, 96, 2430-2439. [CrossRef] [PubMed]

25. Bremner, W.J.; Vitiello, M.V.; Prinz, P.N. Loss of circadian rhythmicity in blood testosterone levels with aging in normal men. J. Clin. Endocrinol. Metab. 1983, 56, 1278-1281. [CrossRef] [PubMed]

26. Morales, A. Testosterone Deficiency Syndrome: An overview with emphasis on the diagnostic conundrum. Clin. Biochem. 2014, 47, 960-966. [CrossRef] [PubMed]

27. Buvat, J.; Lemaire, A. Endocrine screening in 1022 men with erectile dysfunction: clinical significance and cost-effective strategy. J. Urol. 1997, 158, 1764-1767. [CrossRef]

28. Araujo, A.B.; Esche, G.R.; Kupelian, V.; O’Donnell, A.B.; Travison, T.G.; Williams, R.E.; Clark, R.V.; McKinlay, J.B. Prevalence of symptomatic androgen deficiency in men. J. Clin. Endocrinol. Metab. 2007, 92, 4241-4247. [CrossRef]

29. Finkelstein, J.S.; Lee, H.; Burnett-Bowie, S.A.; Pallais, J.C.; Yu, E.W.; Borges, L.F.; Jones, B.F.; Barry, C.V.; Wulczyn, K.E.; Thomas, B.J.; et al. Gonadal steroids and body composition, strength, and sexual function in men. N. Engl. J. Med. 2013, 369, 1011-1022. [CrossRef]

30. Mulhall, J.P.; Trost, L.W.; Brannigan, R.E.; Kurtz, E.G.; Redmon, J.B.; Chiles, K.A.; Lightner, D.J.; Miner, M.M.; Murad, M.H.; Nelson, C.J.; et al. Evaluation and Management of Testosterone Deficiency: AUA Guideline. J. Urol. 2018, 200, 423-432. [CrossRef] 
31. Morales, A.; Bebb, R.A.; Manjoo, P.; Assimakopoulos, P.; Axler, J.; Collier, C.; Elliott, S.; Goldenberg, L.; Gottesman, I.; Grober, E.D.; et al. Diagnosis and management of testosterone deficiency syndrome in men: clinical practice guideline. Can. Med. Assoc. J. 2015, 187, 1369-1377. [CrossRef]

32. Malik, R.D.; Lapin, B.; Wang, C.E.; Lakeman, J.C.; Helfand, B.T. Are we testing appropriately for low testosterone?: Characterization of tested men and compliance with current guidelines. J. Sex. Med. 2015, 12, 66-75. [CrossRef] [PubMed]

33. Malik, R.D.; Lapin, B.; Wang, C.E.; Lakeman, J.C.; Helfand, B.T. Characteristics of men undergoing testosterone replacement therapy and adherence to follow-up recommendations in Metropolitan Multicenter Health Care System. Urology 2015, 85, 1382-1388. [CrossRef] [PubMed]

34. Baillargeon, J.; Urban, R.J.; Kuo, Y.F.; Holmes, H.M.; Raji, M.A.; Morgentaler, A.; Howrey, B.T.; Lin, Y.L.; Ottenbacher, K.J. Screening and monitoring in men prescribed testosterone therapy in the US, 2001-2010. Public Health Rep. 2015, 130, 143-152. [CrossRef]

35. Brand, J.S.; van der Tweel, I.; Grobbee, D.E.; Emmelot-Vonk, M.H.; van der Schouw, Y.T. Testosterone, sex hormone-binding globulin and the metabolic syndrome: A systematic review and meta-analysis of observational studies. Int. J. Epidemiol. 2011, 40, 189-207. [CrossRef] [PubMed]

36. Brambilla, D.J.; Matsumoto, A.M.; Araujo, A.B.; McKinlay, J.B. The effect of diurnal variation on clinical measurement of serum testosterone and other sex hormone levels in men. J. Clin. Endocrinol. Metab. 2009, 94, 907-913. [CrossRef] [PubMed]

37. Trost, L.W.; Mulhall, J.P. Challenges in testosterone measurement, data interpretation, and methodological appraisal of interventional trials. J. Sex. Med. 2016, 13, 1029-1046. [CrossRef] [PubMed]

38. Coviello, A.D.; Kaplan, B.; Lakshman, K.M.; Chen, T.; Singh, A.B.; Bhasin, S. Effects of graded doses of testosterone on erythropoiesis in healthy young and older men. J. Clin. Endocrinol. Metab. 2008, 93, 914-919. [CrossRef] [PubMed]

39. Fernández-Balsells, M.M.; Murad, M.H.; Lane, M.; Lampropulos, J.F.; Albuquerque, F.; Mullan, R.J.; Agrwal, N.; Elamin, M.B.; Gallegos-Orozco, J.F.; Wang, A.T.; et al. Clinical review 1: Adverse effects of testosterone therapy in adult men: A systematic review and meta-analysis. J. Clin. Endocrinol. Metab. 2010, 95, 2560-2575. [CrossRef]

40. Swerdloff, R.S.; Wang, C. Three-year follow-up of androgen treatment in hypogonadal men: preliminary report with testosterone gel. Aging Male 2003, 6, 207-211. [CrossRef]

41. Carter, H.B.; Albertsen, P.C.; Barry, M.J.; Etzioni, R.; Freedland, S.J.; Greene, K.L.; Holmberg, L.; Kantoff, P.; Konety, B.R.; Murad, M.H.; et al. Early detection of prostate cancer: AUA Guideline. J. Urol. 2013, 190, 419-426. [CrossRef]

42. Khera, M.; Bhattacharya, R.K.; Blick, G.; Kushner, H.; Nguyen, D.; Miner, M.M. Changes in prostate specific antigen in hypogonadal men after12 months of testosterone replacement therapy: support for the prostate saturation theory. J. Urol. 2011, 186, 1005-1011. [CrossRef] [PubMed]

43. Ferrucci, L.; Maggio, M.; Bandinelli, S.; Basaria, S.; Lauretani, F.; Ble, A.; Valenti, G.; Ershler, W.B.; Guralnik, J.M.; Longo, D.L. Low testosterone levels and the risk of anemia in older men and women. Arch. Intern. Med. 2006, 166, 1380-1388. [CrossRef] [PubMed]

44. Shahani, S.; Braga-Basaria, M.; Maggio, M.; Basaria, S. Androgens and erythropoiesis: past and present. J. Endocrinol. Invest. 2009, 32, 704-716. [CrossRef] [PubMed]

45. Shin, Y.S.; You, J.H.; Cha, J.S.; Park, J.K. The relationship between serum total testosterone and free testosterone levels with serum hemoglobin and hematocrit levels: A study in $1221 \mathrm{men}$. Aging Male 2016, 19, 209-214. [CrossRef] [PubMed]

46. Roy, C.N.; Snyder, P.J.; Stephens-Shields, A.J.; Artz, A.S.; Bhasin, S.; Cohen, H.J.; Farrar, J.T.; Gill, T.M.; Zeldow, B.; Cella, D.; et al. Association of Testosterone Levels with Anemia in Older Men: A Controlled Clinical Trial. JAMA Intern. Med. 2017, 177, 480-490. [CrossRef] [PubMed]

47. Zhang, L.T.; Shin, Y.S.; Kim, J.Y.; Park, J.K. Could testosterone replacement therapy in hypogonadal men ameliorate anemia, a cardiovascular risk factor? An observational, 54-week cumulative registry study. J. Urol. 2016, 195, 1057-1064. [CrossRef]

48. Saad, F.; Doros, G.; Haider, K.S.; Haider, A. Hypogonadal men with moderate-to-severe lower urinary tract symptoms have a more severe cardiometabolic risk profile and benefit more from testosterone therapy than men with mild lower urinary tract symptoms. Investig. Clin. Urol. 2018, 59, 399-409. [CrossRef] 
49. Ferro, M.; Lucarelli, G.; Bruzzese, D.; Di Lorenzo, G.; Perdonà, S.; Autorino, R.; Cantiello, F.; La Rocca, R.; Busetto, G.M.; Cimmino, A.; et al. Low serum total testosterone level as a predictor of upstaging and upgrading in low-risk prostate cancer patients meeting the inclusion criteria for active surveillance. Oncotarget 2017, 8, 18424-18434. [CrossRef]

50. Bhindi, B.; Locke, J.; Alibhai, S.M.; Kulkarni, G.S.; Margel, D.S.; Hamilton, R.J.; Finelli, A.; Trachtenberg, J.; Zlotta, A.R.; Toi, A.; et al. Dissecting the association between metabolic syndrome and prostate cancer risk: Analysis of a large clinical cohort. Eur. Urol. 2015, 67, 64-70. [CrossRef]

51. de Cobelli, O.; Terracciano, D.; Tagliabue, E.; Raimondi, S.; Galasso, G.; Cioffi, A.; Cordima, G.; Musi, G.; Damiano, R.; Cantiello, F.; et al. Body mass index was associated with upstaging and upgrading in patients with low-risk prostate cancer who met the inclusion criteria for active surveillance. Urol. Oncol. 2015, 33, 201.e1-201.e8. [CrossRef]

(C) 2019 by the authors. Licensee MDPI, Basel, Switzerland. This article is an open access article distributed under the terms and conditions of the Creative Commons Attribution (CC BY) license (http://creativecommons.org/licenses/by/4.0/). 